\title{
Genome-wide identification and expression analysis of CILAX, CIPIN and CIABCB genes families in Citrullus lanatus under various abiotic stresses and grafting
}

\author{
Chenliang Yu', Wenqi Dong ${ }^{1}$, Yihua Zhan², Zong-an Huang ${ }^{3}$, Zhimiao $\mathrm{Li}^{1}, \|$ Seop Kim${ }^{4}$ and Chenghao Zhang ${ }^{1 *}$
}

\begin{abstract}
Background: Auxin plays an important role in regulating plant growth and development as well as in the response of plants to abiotic stresses. Auxin is transported by three kinds of major protein families, including the AUXIN RESISTANT 1/LIKE AUX1 (AUX/LAX) influx carriers, the PIN-FORMED (PIN) efflux carriers and the ATP binding cassette B/P-glycoprotein/Multidrug-resistance (ABCB/MDR/PGP) efflux/condition carriers. The biological function of several auxin transporter genes has been well characterized in Arabidopsis thaliana. However, their function in response to exogenous auxin and abiotic stresses in watermelon (Citrullus lanatus. L) remained unknown.

Results: Here, the latest updated watermelon genome was used to characterise the CILAX, CIPIN and CIABCB family genes from watermelon. The genome-wide analysis of the CILAX, CIPIN and CIABCB family genes, including chromosome localisation, gene structure, and phylogenic relationships, was carried out. Seven CILAXS, 11 CIPINS and 15 $C I A B C B s$ were mapped on 10 watermelon chromosomes. The expression profiles of the CILAX, CIPIN and CIABCB genes under exogenous indole-3-acetic acid and various abiotic stresses (salt, drought, and cold stresses) treatments were performed by quantitative real-time PCR (qRT-PCR). The transcriptional level of majority CILAX, CIPIN and CIABCB genes were changed by abiotic stresses in both shoots and roots. We also analysed the expression levels of CILAX, CIPIN and $C I A B C B$ genes in graft response.
\end{abstract}

Conclusion: Analysis of the expression patterns of CILAX, CIPIN and CIABCB genes under salt, drought, cold treatment and grafting response helps us to understand the possible roles of auxin transporter genes in watermelon adaptation to environmental stresses.

Keywords: $A B C B$, Abiotic stresses, Grafting, LAX, PIN, Watermelon

\section{Background}

Auxin is a very important plant hormone involved in regulating many processes of plant growth and development, such as root formation, apical dominance, inflorescence and phyllotaxy development, vascular tissue differentiation, fruit maturation and responses to illumination and gravity. Abnormal phenotypes are observed in plants, which are caused by excessive or insufficient concentrations of endogenous auxin [1]. Plants are inevitably subject to abiotic

\footnotetext{
* Correspondence: sheshizaipei@163.com

${ }^{1}$ Vegetable Research Institute, Zhejiang Academy of Agricultural Sciences,

Hangzhou 310021, China

Full list of author information is available at the end of the article
}

stresses such as salinity, cold, high temperature and drought during the life cycle. Auxin plays a key role in plant response to stress $[2,3]$ and environmental stress response relies on auxin homeostasis within different plant tissues [4]. The homeostasis of auxin is often disturbed by abiotic stress, which leads to the change of plant growth and development $[5,6]$.

Auxin is primarily synthesised in apical meristems and developing leaf tips, then transported to distal target tissues either through the bulk flow in stem vascular tissues in a non-polar free diffusion or actively in a polar transport [7]. Auxin transport exhibits polarity, which is unique among all phytohormones. The polar transport 
of auxin is mediated through the auxin carriers, including AUXIN RESISTENT1/LIKE AUX1 (AUX/ LAX) influx carrier, PIN-FORMED (PIN) efflux carriers, and ATP binding cassette B/P- glycoprotein/Multidrug-resistance (ABCB/MDR/PGP) efflux/condition carriers [8-10].

$A U X / L A X$ family is a subclass of amino acid superfamily recognized as auxin input carrier family. AtAUX 1 is the first $A U X / L A X$ family gene cloned in Arabidopsis, which encoded a protein containing 11 transmembrane structure [8]. Mutations of $A U X / L A X$ show the auxinrelated developmental defects in Arabidopsis thaliana. Ataux1 mutants are agravitropic and selective resistant to auxin [11]. They are insensitive to indole-3-acetic acid (IAA) and (2, 4-dichlorophenoxy)-aceticacid (2, 4-D). Only free diffusion of naphthalene-1-acetic acid (NAA) can restore the gravitropism of ataux1 [11, 12]. AtLAX3 and AtAUX1 co-ordinately regulate lateral root development by regulating the emergence and initiation of lateral root primordia [13, 14]. AtAUX1 and AtLAX3 are high-affinity auxin transporters by auxin uptake experiments in heterologous expression systems $[13,15,16]$. Disruption of the AtLAX2 gene results in increasing division of the cells in the quiescent centre (QC) and decreasing expression of AtWOX5 and the auxin response reporter DR5 [17]. The $A U X \angle A X$ gene family affects phyllotactic patterning and is needed to establish the embryonic root cell organization and plant embryogenesis in Arabidopsis [18, 19]. PaLAX1, from wild cherry (Prunus avium), promotes the absorption rate of auxin in cells and affects the distribution of free endogenous auxin [20]. OsAUX1 controls the lateral root initiation, primary root and root hair elongation in rice [21, 22]. In sorghum, maize (Zea mays) and soybean (Glycine max), some $A U X /$ $L A X$ genes are in response to hormonal and abiotic stress at transcriptional level [23-25].

Among the auxin carriers, PIN family is extensively studied in Arabidopsis. The PIN family was first cloned and comprised of eight members in Arabidopsis [26]. The PIN family genes play crucial roles in various aspect of developmental processes, including root meristem patterning, root hair growth, lateral root development, vascular bundle differentiation, phototropism and embryo development [27-29]. PIN proteins are localised either on the plasma membrane (AtPIN1, $-2,-3,-4$ and $-7)$ or in the endoplasmic reticulum (ER) (AtPIN5, AtPIN6 and AtPIN8). PIN proteins also play a vital role in both intracellular and intercellular auxin homeostasis $[30,31]$. The PIN efflux transporter asymmetric localisation on the plasma membrane regulates the direction of the flow of auxin [32]. For example, AtPIN1 is asymmetrically localised on the basal rootward face of vascular cells [33]. The study of the PIN family has been expanded to other species not limited to Arabidopsis. In maize (Zea mays), two putative orthologues of AtPIN1, ZmPIN1a and ZmPIN1b, have been analysed involving in endosperm and embryonic development [34, 35]. In rice (Oryza sativa), as the closest orthologue of AtPIN1, OsPIN1b is been detected expressed in the roots, stem base, stem, leaves and young panicles [36, 37]. By analysis the phenotype of overexpression and RNAi lines, OsPIN1b may involve in auxin transport in primary and adventitious roots in rice [36]. The auxin transport from the shoot to the root-shoot junction is increased in OsPIN2 overexpression plants. Overexpression of OsPIN2 resulted in a larger tiller angle, a lowered plant height and an increased tiller number compared with the wild type [38]. A putative auxin efflux carrier of rice, OsPIN3t, is involved in the drought stress response and drought tolerance [39]. Three monocot-specific PIN genes from rice, OsPIN9, OsPIN10a, and OsPIN10b, are expressed at high level in adventitious root primordia and pericyclic cells at the stem base, suggesting that they might be involved in adventitious root development [37].

The ATP-binding cassette $(\mathrm{ABC})$ superfamily contains more than 100 members in plants [40]. The subfamily $B$ $(\mathrm{ABCB})$, previously known as multidrug resistance (MDR)/phospho-glycoprotein (PGP) proteins, some of them are involved in auxin transport [41, 42]. Six members of ABCB transporters in Arabidopsis (AtABCB1, -4, $-14,-15,-19$ and -21 ) have been associated with auxin transport [41-44]. To date, AtABCB1, AtABCB4 and $A t A B C B 19$ are the best characterised $A B C B$ s. Both AtABCB1 and AtABCB19 are involved in auxin efflux. AtABCB1 and AtABCB19 coordinate with AtPIN1 in long distance transport of auxin along the plant main axis, and regulate root and cotyledon development [45-47]. AtABCB4 and AtABCB21 function as an efflux and influx carrier that controls cellular auxin levels [44, 48]. AtABCB14 was first described as a malate importer modulating stomata aperture response to $\mathrm{CO}_{2}$ levels [49]. AtABCB14 and AtABCB15 are expressed in vascular tissues of primary stem by promoter::glucuronidase reporter assays. Anatomical alterations of the vascular tissue of the primary stem have been shown and IAA transport along the inflorescence is reduced in both atabcb14 and atabcb15 mutants, these results suggesting AtABCB14 and AtABCB15 might participate in auxin transport [43]. $O s A B C B 14$, a rice gene high homology with $A t A B C B 1$ and $A t A B C B 19$, has been demonstrated as an auxin influx transporter, and its knockout mutants are insensitive to 2 , 4-D and IAA. OsABCB14 was found to be involved in iron homeostasis in rice [50].

Recently, auxin transporter genes have been studied throughout the plant kingdom, such as Medicago sativa, Glycine max, Populus trichocarpa, Prunus avium, Oryza sativa, Sorghum bicolor, and Zea mays [20, 23-25, 51]. However, little or nothing is known about the $L A X$, PIN 
and $A B C B$ families in watermelon (Citrullus lanatus) to date. Watermelon is an important cucurbit crop and its output value accounted for more than $10 \%$ of the total output value of the vegetable industry in China. Watermelon seedling's growth stops below $10{ }^{\circ} \mathrm{C}$ and cannot survive below the $1{ }^{\circ} \mathrm{C}$ [52]. Salinity and drought are the major environmental stresses in plant agriculture worldwide. Grafting is widely used to improve plants adaptation to biotic or abiotic stress [53, 54]. However, the expression of auxin transporter genes underlying grafting processes remains unclear. In this study, we provides comprehensive information on the ClLAX, ClPIN and ClABCB gene families and expression patterns of those genes exposed to salt, drought and cold stresses. The distinctive tissuespecific expression patterns of the ClLAX, ClPIN and $C l A B C B$ genes, and their differential responses to salt, drought and cold stresses are the molecular basis to increase abiotic stress tolerance in watermelon. Our studies also provide a new insight into the expression of ClLAX, $C l P I N$ and $C l A B C B$ gene families at the phase of grafting.

\section{Methods}

Plant material, growth conditions and stress treatments

Watermelon "zaojia" was selected in this study. Seeds were sown in perlite beds after sterilized with $10 \%$ sodium hypochlorite for $30 \mathrm{~min}$. Seedlings at the two-leaf were irrigated by half-strong Hoagland solution (pH5.6). The growth conditions were as follows: a $12 \mathrm{~h}$ photoperiod under fluorescent light $\left(600 \mu \mathrm{E} \mathrm{m}^{2} \mathrm{~s}^{-1}\right)$ at with $60 \%$ relative humidity, and temperature of $28 / 18{ }^{\circ} \mathrm{C}$ (day/night). A month old seedlings were used for stress treatment.

For auxin treatment, the roots of watermelon seedlings were soaked in half-strong Hoagland nutrient solution containing $100 \mu \mathrm{M}$ IAA. For salt stress experiment, the roots of seedlings were immersed in nutrient solution containing $200 \mathrm{mM} \mathrm{NaCl}$. For drought stress experiment, the roots of seedlings were immersed in nutrient solution containing 20\% (W/W) PEG6000 (Polyethylene glycol). For cold treatment, seedlings were transferred to a $4{ }^{\circ} \mathrm{C}$ growth chamber. Then root and shoot samples of watermelon seedlings at different treatment time points were harvested. For graft experiment, watermelon plants when cotyledon had expanded were grafted onto squash performed by 'top approach grafting' method. Experiment was repeated for 3 times with similar results.

For tissue-specific expression analysis, roots, stems, leaves, and cotyledons samples were harvested from twoleaf stage; for flower samples, flowers were harvested at 2 $\mathrm{d}$ after opening.

\section{Identification of CILAX, CIPIN and CIABCB auxin transporter family genes in watermelon}

The sequences of ClLAX, ClPIN and ClABCB were collected by homology screening against Cucurbit Genomics
Database (http://www.icugi.org/cgi-bin/ICuGI/index.cgi) (version 1). The known sequences of AtLAX, AtPIN and $A t A B C B$ were used as queries. The hidden Markov model profiles were used to identify LAX, PIN and ABCB proteins from the proteome of watermelon. Pfam 01490 (Transmembrane amino acid transporter protein) was used for ClLAX proteins identification; Pfam 03547 (Membrane transport protein) was used for ClPIN proteins identification; Pfam 00005(ABC transporter) and Pfam 00664 (ABC transporter transmembrane region) were used for $\mathrm{ClABCB}$ proteins identification. Protein molecular weight and isoelectric point were predicted by DNAstar tool (http:// www.dnastar.com/). The transmembrane helices of CILAX, CIPIN and ClABCB proteins were predicted by TMHMM2 Software (http://www.cbs.dtu.dk/services/TMHMM/).

\section{Genome distribution, phylogenetic tree building and intron/exon structure}

The chromosomal location data of CLLAX, CIPIN and $C l A B C B$ family genes were obtained from Cucurbit Genomics Database. A map of the distribution of ClLAX, $C l P I N$ and $C l A B C B$ family genes was drawn based on their chromosomal position. The alignment file of LAX, PIN and $\mathrm{ABCB}$ family proteins in watermelon and Arabidopsis was generated by ClustalW program with the default parameters. The amino acid sequences of AtLAX, AtPIN and AtABCB proteins were obtained from Yue et al. [24]. Phylogenetic tree was performed by MEGA6.0 (http:// www.megasoftware.net/) using the neighbor-joining (NJ) method with the $\mathrm{p}$-distance and complete deletion parameters. Exon-intron structure of ClLAX, ClPIN and ClABCB family genes were employed by Gene Structure Display Server (GSDS) tool (http://gsds.cbi.pku.edu.cn/).

\section{Quantitative real time-polymerase chain reaction PCR (qRT-PCR)}

Total RNA were extracted from $0.1 \mathrm{~g}$ of samples using MiniBEST Plant RNA Extraction Kit (code: 9769, TAKARA, Japan) according to the manufacturer's instruction. The primers sequences of qRT-PCR are listed in Additional file 1: Table S1. Quantitative RT-PCR was performed on LightCycler480 instrument (Roche) according to the manufacturer's instructions. The ClACTIN (Cla004014) was used as internal standards basing on the comparative cycle threshold $\left(2^{-\Delta \Delta C t}\right)$ values. Heat map was performed by $\mathrm{MeV}$ software using the average $\mathrm{Ct}$ value to visualize the tissues-specific expression data. All the expression analyses were carried out with three biological repeats.

\section{Results}

Genome-wide identification of CILAX, CIPIN and CIABCB genes in watermelon

In the present study, we used the AUX/LAX, PIN and $\mathrm{ABCB}$ full-length protein sequences from Arabidopsis as 
BLAST queries to search Cucurbit Genomics Database (http://www.icugi.org/). Four hidden Markov model profiles (Pfam 01490, Pfam 03547, Pfam 00005 and Pfam 00664) were used to identify the CILAX, CIPIN and ClABCB proteins. Totally seven ClLAX genes, 11 ClPIN genes and $15 C l A B C B$ genes were identified. We named them based on their order on the chromosomes. Information on ClLAX, ClPIN and ClABCB gene families, including gene names, locus ID, open reading lengths, exon numbers, chromosome locations and deduced polypeptide parameters, were listed in Table 1.

The sizes of the ORF for the ClLAX genes ranged from $1326 \mathrm{bp}$ (ClLAX3) to $1470 \mathrm{bp}$ (ClLAX1), and the sizes of the corresponding proteins were between 441 and 489 amino acids. The molecular masses of CILAX protein varied from $49.5 \mathrm{kDa}$ (ClLAX6) to $54.96 \mathrm{k} \mathrm{Da}$ (CILAX1). The predicted isoelectric points ranged from 7.804 (ClLAX4) to 9.258 (ClLAX2). The number of transmembrane of ClLAX proteins predicted by TMHMM2 software was between 8 and 10. The sizes of the ORF for the ClPIN genes ranged from $564 \mathrm{bp}$ (ClPIN3) to 1926 bp (ClPIN1). The sizes of the corresponding proteins were between 187 and 641 amino acids. The molecular masses of CIPIN protein varied from $19.89 \mathrm{kDa}$ (ClPIN3) to $69.9 \mathrm{k} \mathrm{Da}$ (ClPIN1). The predicted isoelectric points varied from 5.453 (ClPIN3) to 10.852 (CIPIN8). The sizes of the ORF for the $C l A B C B$ genes ranged from $3504 \mathrm{bp}$ ( $C l A B C B 5)$ to $4368 \mathrm{bp}$ (ClABCB9), and the sizes of the corresponding proteins are between 1167 and 1455 amino acids. The molecular masses of $\mathrm{ClABCB}$ protein varied from $127.97 \mathrm{kDa}$ (ClABCB5) to $159.17 \mathrm{kDa}$ (ClABCB9). The predicted isoelectric points varied from 6.722 (ClABCB13) to 9.286 (ClABCB5).

Chromosomal distribution of CILAX, CIPIN and CIABCB genes Based on position of ClLAX, ClPIN and ClABCB genes on the watermelon chromosomes, we mapped all 33 genes of ClLAX, ClPIN and ClABCB family on chromosomes (Fig. 1a, Table 1). The 33 genes were unevenly distributed on 10 out of the 11 watermelon chromosomes. Among 33 genes, not a single gene was located on chromosome 8 . Chromosome 3 only contained one gene. Two genes were located on chromosome 1, 6 and 11, respectively. Three genes were distributed on each of chromosomes 4 and 7. Seven genes were located on chromosome 2 (Fig. 1a). In many plants, including S.bicolor, Arabidopsis, G.max, O.sativa, some of the auxin transporter genes were clustered. Three small gene clusters were identified in accord with the definition of gene clusters [55]. Two gene clusters were distributed on chromosome 2 (Fig. 1a). The other one was distributed on chromosome 7 . The first gene cluster contained two $C l A B C B$ genes $(C l A B C B 2$ and $C l A B C B 3)$. The second gene cluster contained two ClPIN genes (CIPIN2 and
ClPIN3). The third gene cluster contained two ClPIN genes (ClPIN8 and ClPIN9).

Gene duplication is the main contributor to evolutionary momentum [56]. The duplication patterns of ClLAX, $C I P I N$ and $C l A B C B$ families including tandem and segmental duplications were analyzed to find the expansion of $C L L A X, C I P I N$ and $C I A B C B$ gene families during the evolutionary momentum. Tandem duplication was observed between ClABCB2 and ClABCB3 (Fig. 1b). ClLAX3/ ClLAX5 gene pairs share high similarity in protein sequences (Additional file 2: Table S2), and were lactation on different chromosomes, indicating that they were segmental duplicated gene pair. Three segmental duplications occurred in the $C l A B C B$ gene family: $C l A B C B 4 / C l A B C B 15$, $C l A B C B 6 / C l A B C B 8$ and $C l A B C B 11 / C l A B C B 14$ (Fig. 1b).

\section{Phylogenetic relationship analysis of the CILAX, CIPIN and $C I A B C B$ family genes}

Many studies revealed the biological functions of the auxin transporter genes in Arabidopsis [11, 29, 42]. Investigation of the evolutionary relationships of three kinds of auxin transporter proteins between watermelon and Arabidopsis helps us to understand the possible biological functions of these auxin carriers in watermelon. Multiple protein sequence alignments of full-length amino acid sequence were carried out using the MEAG6.0 software for phylogenetic analysis with the neighbour-joining method. A total of 11 AUX/LAX proteins, including 7 ClLAX proteins and 4 AtLAX proteins were used to build a phylogenetic tree (Fig. 2a). The $L A X$ family genes could be divided into two subfamilies (subfamily I and subfamily II). Six of them belong to subfamily I (ClLAX3, 4, 5, 6, AtAUX1 and AtLAX1). A paralogue gene pair existed in the watermelon $L A X$ family: ClLAX4/ClLAX6. A total of 19 PIN proteins, including 11 CIPIN proteins and 8 AtPIN proteins were used to construct a phylogenetic tree (Fig. 2b). All the PIN family could be grouped into five subfamilies (subfamily I, -II, -III, -IV and-V). Two PIN orthologue gene pairs existed between watermelon and Arabidopsis: ClPIN6/AtPIN2 and ClPIN10/AtPIN6. A total of $37 \mathrm{ABCB}$ proteins, including $15 \mathrm{ClABCB}$ proteins and 22 AtABCB proteins were used to construct a phylogenetic tree (Fig. 2c). All the ABCB families could be classified into three subfamilies (subfamily I, subfamily II and subfamily III). Two ABCB orthologue gene pairs were existed between watermelon and Arabidopsis: $C l A B C B 14 / A t A B C B 1$ and $C l A B C B 11 / A t A B C B 19$. Two paralogue gene pair occurred in the watermelon $A B C B$ family: $C l A B C B 2 / C l A B C B 3$ and $C l A B C B 6 / C l A B C B 8$.

\section{Analysis of tissue-specific expression and gene structure of CILAX, CIPIN and CIABCB family genes}

To elucidate the biological roles of different members of the ClLAX,ClPIN and ClABCB family in watermelon, 
Table 1 Information on CILAX, CIPIN and CIABCB genes and properties of the deduced proteins in watermelon (Citrullus lanatus)

\begin{tabular}{|c|c|c|c|c|c|c|c|c|}
\hline \multirow[t]{2}{*}{ Gene } & \multirow[t]{2}{*}{ Locus ID } & \multirow{2}{*}{$\begin{array}{l}\text { ORF } \\
\text { lengh (bp) }\end{array}$} & \multirow{2}{*}{$\begin{array}{l}\text { No. of } \\
\text { extrons }\end{array}$} & \multirow{2}{*}{$\begin{array}{l}\text { Chromosome } \\
\text { No. }\end{array}$} & \multicolumn{3}{|c|}{ Deducted polypeptid } & \multirow{2}{*}{$\begin{array}{l}\text { No. of } \\
\text { transmembrane }\end{array}$} \\
\hline & & & & & Length (aa) & Ml wt (Da) & $\mathrm{pl}$ & \\
\hline CILAX1 & Cla015837 & 1470 & 8 & Chr2 & 489 & 54960.23 & 8.927 & 10 \\
\hline CILAX2 & Cla020298 & 1461 & 8 & Chr2 & 486 & 54841.35 & 9.258 & 10 \\
\hline CILAX3 & Cla018110 & 1326 & 7 & Chr4 & 441 & 49895.36 & 8.204 & 8 \\
\hline CILAX4 & Cla004339 & 1467 & 7 & Chr7 & 488 & 54875.07 & 7.804 & 10 \\
\hline CILAX5 & Cla017975 & 1437 & 7 & Chr10 & 478 & 53841.09 & 8.331 & 10 \\
\hline CILAX6 & Cla006581 & 1329 & 8 & Chr11 & 442 & 49504.24 & 8.485 & 8 \\
\hline CILAX7 & Cla000681 & 1443 & 8 & chro & 480 & 54063.26 & 8.532 & 10 \\
\hline CIPIN1 & Cla003909 & 1926 & 6 & chr1 & 641 & 69903.01 & 7.439 & 9 \\
\hline CIPIN2 & Cla010530 & 1041 & 5 & chr2 & 346 & 37608.62 & 7.982 & 8 \\
\hline CIPIN3 & Cla010532 & 564 & 3 & chr2 & 187 & 19891.53 & 5.453 & 2 \\
\hline CIPIN4 & Cla012098 & 1848 & 6 & chr4 & 615 & 65610.47 & 7.899 & 8 \\
\hline CIPIN5 & Cla018455 & 1860 & 6 & chr4 & 619 & 67586.08 & 9.088 & 9 \\
\hline CIPIN6 & Cla018871 & 1896 & 6 & chr6 & 631 & 69221.59 & 9.178 & 5 \\
\hline CIPIN7 & Cla018924 & 1824 & 7 & chr6 & 607 & 66418.92 & 9.149 & 9 \\
\hline CIPIN8 & Cla011709 & 1005 & 5 & chr7 & 334 & 36418.55 & 10.852 & 2 \\
\hline CIPIN9 & Cla011708 & 675 & 1 & chr7 & 224 & 25017.54 & 7.190 & 5 \\
\hline CIPIN10 & Cla015026 & 1449 & 5 & chr9 & 482 & 53345.51 & 9.198 & 6 \\
\hline CIPIN11 & Cla017028 & 1092 & 6 & chr10 & 363 & 40031.79 & 9.761 & 7 \\
\hline$C I A B C B 1$ & Cla009733 & 3765 & 12 & chr1 & 1254 & 135542.15 & 7.431 & 10 \\
\hline$C I A B C B 2$ & Cla006778 & 3675 & 10 & chr2 & 1224 & 134618.81 & 7.096 & 11 \\
\hline$C I A B C B 3$ & Cla006779 & 3708 & 10 & chr2 & 1235 & 135741.22 & 7.262 & 11 \\
\hline CIABCB4 & Cla010534 & 3897 & 12 & chr2 & 1298 & 139885.34 & 8.658 & 10 \\
\hline CIABCB5 & Cla011266 & 3504 & 9 & chr3 & 1167 & 127972.37 & 9.286 & 8 \\
\hline CIABCB6 & Cla001708 & 3750 & 7 & chr 5 & 1249 & 137870.07 & 8.638 & 12 \\
\hline$C I A B C B 7$ & Cla007439 & 3906 & 12 & chr5 & 1301 & 141742.47 & 7.289 & 11 \\
\hline CIABCB8 & Cla010011 & 3780 & 7 & chr 5 & 1259 & 137952.57 & 8.756 & 9 \\
\hline CIABCB9 & Cla015527 & 4368 & 9 & chr9 & 1455 & 159168.71 & 8.788 & 12 \\
\hline$C I A B C B 10$ & Cla016230 & 3612 & 12 & chr9 & 1203 & 131803.14 & 8.908 & 10 \\
\hline$C I A B C B 11$ & Cla010337 & 3753 & 10 & chr9 & 1250 & 136474.22 & 8.189 & 10 \\
\hline$C I A B C B 12$ & Cla010365 & 3750 & 7 & chr9 & 1249 & 135971.07 & 8.733 & 9 \\
\hline$C I A B C B 13$ & Cla004699 & 4200 & 11 & chr9 & 1399 & 155709.89 & 6.722 & 12 \\
\hline CIABCB14 & Cla017800 & 4080 & 9 & chr10 & 1359 & 148875.01 & 6.949 & 11 \\
\hline$C I A B C B 15$ & Cla022922 & 3633 & 11 & chr11 & 1210 & 130903.31 & 8.198 & 8 \\
\hline
\end{tabular}

the expression of ClLAX, ClPIN and $C l A B C B$ genes was investigated in different tissues performed by quantitative real-time polymerase chain reaction (qRT-PCR). Total RNA was extracted from the roots, cotyledons, mature leaves, stems and flowers of watermelon. All transcripts of ClLAX, ClPIN and ClABCB family genes were detected in the selected tissues. Most of the ClLAX,CIPIN and $C l A B C B$ genes showed different tissue-specific patterns across the five tissues. As shown in Fig. 3a, the transcriptional level of the ClLAX family gene was the highest in the mature leaves and the lowest in the flowers. ClPIN3 and ClPIN5 were highly expressed in roots. ClPIN1, CIPIN8 and ClPIN11 showed the highest level of expression in mature leaves. Most of ClPIN genes were weakly expressed in the flowers. $C l A B C B 3$ was much more highly expressed than any other $C l A B C B$ genes in the flowers. The level of expression of $C l A B C B$ genes was much higher in the stems than in the flowers. All the expression levels of the ClLAX, ClPIN and ClABCB family genes in five tissues are listed in Additional file 3: Table S3. 


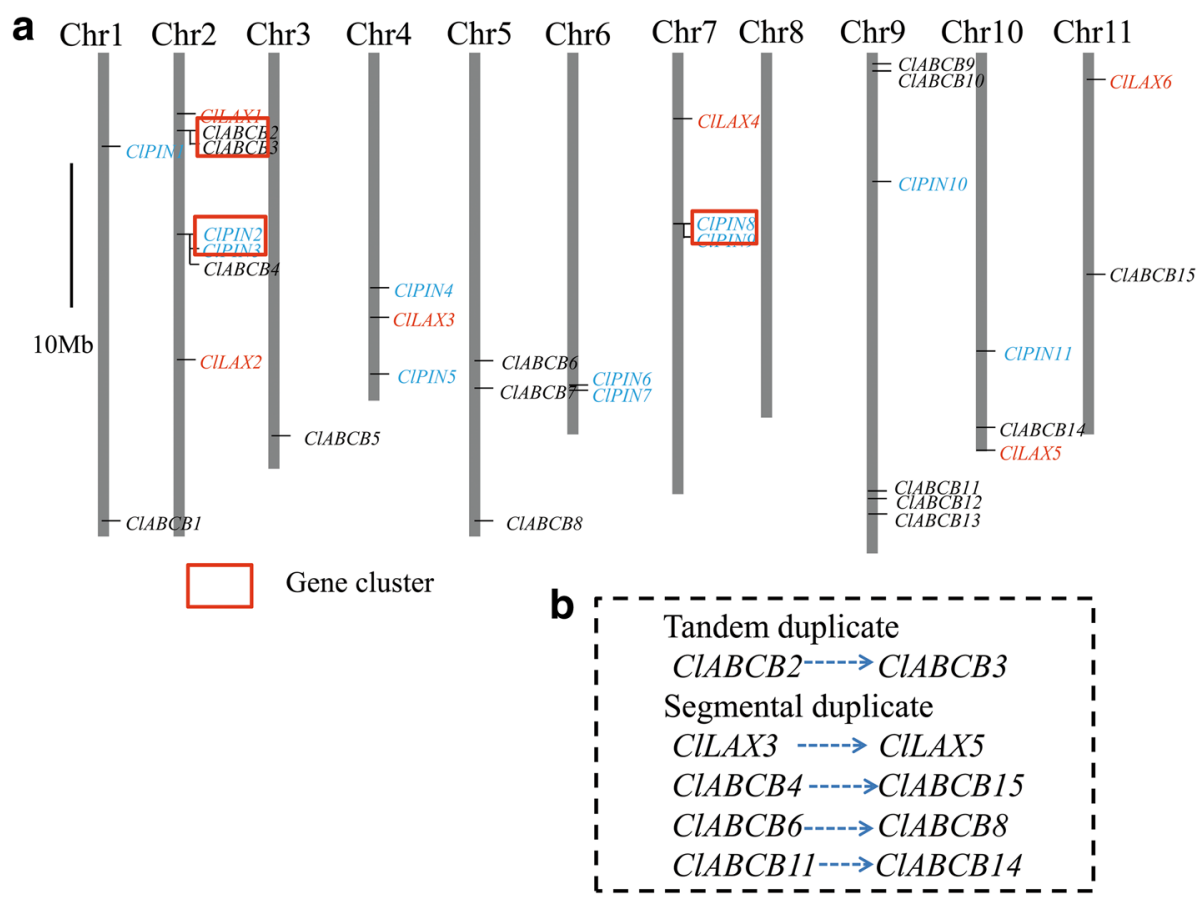

Fig. 1 Chromosomal distributionsand expansion patterns of CILAX, CIPIN and CIABCB family genes in watermelon. a The genome visualization tool SyMAP Synteny Browser was employed to analyze the watermelon genome. Watermelon chromosomes were arranged in blocks. Seven CILAX genes, 11 CIPIN genes and 15 CIABCB genes were mapped by locus. Red boxes presented the gene clusters. $\mathbf{b}$ Tandem duplicate $C / A B C B 2 / C I A B C B 3$ and Four pairs of segmental duplicates $C I A B C B 4 / C I A B C B 13, C I A B C B 6 / C I A B C B 8$, $C I A B C B 11 / C I A B C B 14$ were showed with dotted arrows. Scale bar represents $10 \mathrm{Mb}$

Gene structure analysis of the ClLAX, ClPIN and $C l A B C B$ family genes was revealed by comparing the coding sequences with genomic DNA sequences. The exon-intron structures of the three family genes revealed variations (Fig. 3b). The gene exon number of ClLAX genes was either seven or eight. The number of exons in ClPIN genes varied from one (ClPIN9) to seven (ClPIN7). The number of exons in $C l A B C B$ genes varied from 7 to 12 .

\section{Expression profiles of CILAX, CIPIN and CIABCB family genes upon IAA treatment}

Auxin regulating plant growth and development depends mainly on auxin transporter to regulate auxin relocation and homeostasis [23, 24]. Exogenous auxin treatment could accelerate or block the endogenous auxin transport between different tissues [23, 57]. To investigate whether the auxin transporters in watermelon were regulated by auxin, the expression profiles of ClLAX, ClPIN and $C l A B C B$ genes under $10 \mu \mathrm{M}$ IAA for $9 \mathrm{~h}$ in the shoots and roots were analysed by qRT-PCR (Fig. 4). Total RNA was isolated from the shoots and roots of mock seedlings or IAA-treated seedlings at different time points $(6,12$ and $24 \mathrm{~h}$ ). Our data suggested that most CILAX, CIPIN and $C l A B C B$ genes were auxin responsive genes. The majority of these genes were differentially regulated by IAA at the transcriptional level. IAA treatment increased the expression levels of ClLAX1, -7, ClPIN3,-4, -5, -6, -7 and $C l A B C B 4$ in the shoots more than five-fold. On the contrary, $C l A B C B 1,-2,-5,-10$ and -14 expression levels were downregulated in the shoots after IAA treatment (Fig. 4a). Most of the auxin transporter genes were upregulated after IAA treatment in the roots (Fig. 4b). IAA treatment upregulated the expression levels of ClLAX1, $-2,-3$, ClPIN3, -7, ClABCB2, -10 and -12 more than15fold in the roots. In both the roots and shoots, the expression of $C l A B C B 5$ was down-regulated by IAA treatment.

\section{Expression Profiles of CILAX, CIPIN and CIABCB family genes under abiotic stresses}

Watermelon is one of the most drought and salinity sensitive cucurbit crops. Its yield is significantly influenced by these abiotic stresses such as drought, salinity and cold [52]. Many studies showed that auxin is involved in stress response, and a quantity of auxin transporter genes are associated with abiotic stress responses. To investigate whether ClLAX, CIPIN and ClABCB genes are involved in abiotic stress response, the expressions levels of 33 auxin transporter genes were investigated under salinity $(\mathrm{NaCl})$, drought (PEG) and cold $\left(4{ }^{\circ} \mathrm{C}\right)$ treatment using qRT-PCR (Figs. 5, 6 and 7). Untreated seedlings growing under normal condition were used as control. 

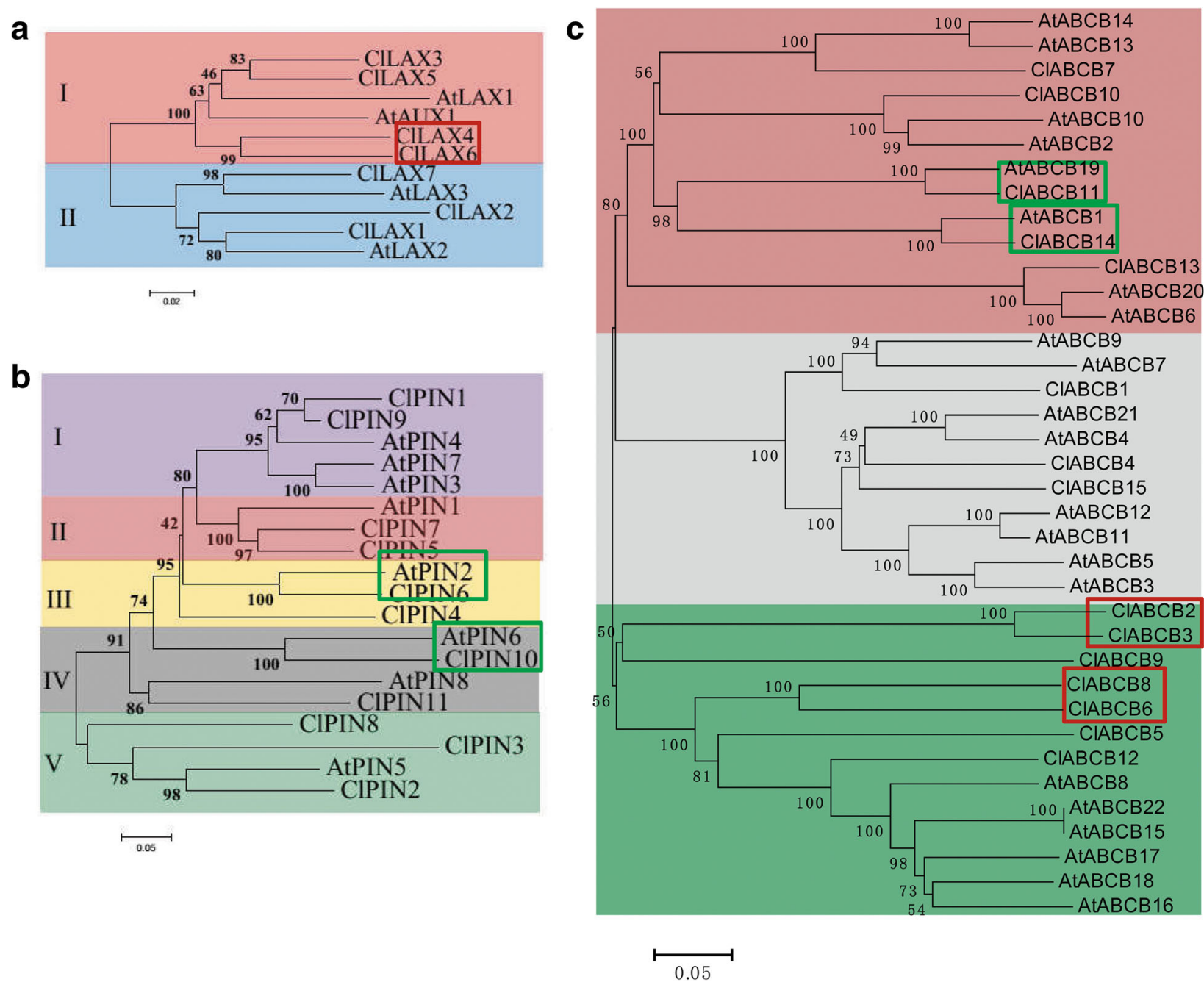

Fig. 2 Phylogenetic relationship analysis of $L A X(\mathbf{a})$, PIN (b) and ABCB (c) family between watermelon and Arabidopsis. All branches were marked with bootstrap values. Inventory of AtLAX, AtPIN families is based on TAIR databases. The paralogous genes between watermelon and Arabidopsis were indicated by green boxes. The orthologous genes within watermelon were indicated by red boxes

Different ClLAX, ClPIN and ClABCB expression patterns were observed in the roots and shoots when they were treated with the abiotic stress treatment. The majority of the ClLAX, ClPIN and ClABCB genes were downregulated in the shoots after $200 \mu \mathrm{M} \mathrm{NaCl}$ treatment (Fig. 5a). However, most of the ClLAX, ClPIN and $C l A B C B$ genes were upregulated in the roots after $\mathrm{NaCl}$ treatment (Fig. $5 \mathrm{~b}$ ). Only the expression of ClLAX6, ClPIN2, and ClABCB5 was inhibited by $\mathrm{NaCl}$ treatment in the roots. Half of ClLAX, ClPIN and ClABCB genes were upregulated in the shoots under PEG treatment (Fig. 6a). ClLAX3, -4, ClPIN4, -6, -7, -10, -11, $C l A B C B 1,-2,-3,-4,7,-8,-9$ and -15 were induced ( $>5$ fold) by PEG treatment after $24 \mathrm{~h}$ in the shoots. However, only ClPIN7, ClABCB12 and ClABCB13 were induced ( $>5$ fold) by PEG treatment after $24 \mathrm{~h}$ in the roots (Fig. 6b). Half of ClLAX, ClPIN and ClABCB genes were upregulated in shoots under cold treatment for $24 \mathrm{~h}$ (Fig. 7a). The expression of ClLAX2, ClPIN4, -5 , $-7, C l A B C B 7,-8,-9,-11$ and -13 were down-regulated in the roots by cold treatment (Fig. $7 \mathrm{~b}$ ).

\section{Expression profiles of CILAX, CIPIN and CIABCB family genes in grafting response}

Grafting is an ancient technique that is widely used in agriculture practices to improve productivity and stress resistance [53]. Auxin can increase the activity of cell division and wound healing in cut Arabidopsis inflorescence stems. However, the molecular mechanisms of auxin involved in these processes remain largely unclear. To investigate whether auxin transporter genes from watermelon are involved in grafting response, we analysed the expression profiles of ClLAX, ClPIN and $C l A B C B$ during grafting for 5 days in the shoots (Fig. 8). 


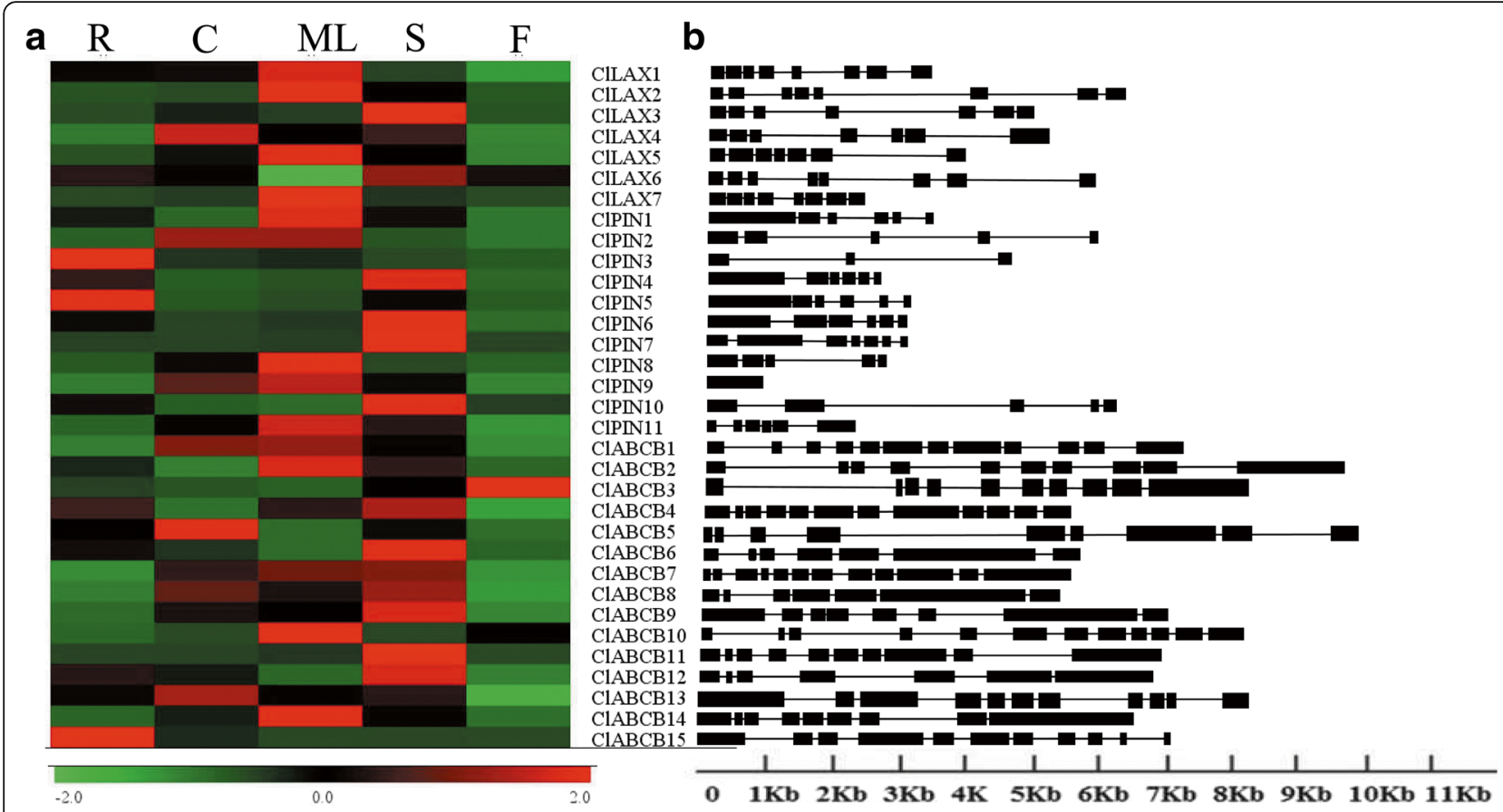

Fig. 3 Analysis of tissues-specific expressions (a) and exon-intron structures (b) of CILAX, CIPIN and CIABCB genes. R: root; C: cotyledon; ML: mature leaf; S: shoot; F: flower. Levels of different colours were shown on expression scale of each CILAX, CIPIN and CIABCB genes. The exons were indicated by black boxes; the introns were indicated by black lines

The data indicated that most of the ClLAX genes were downregulated and most of the CIPIN genes were upregulated in the shoots during grafting. Only $C l A B C B 1,-7$, -11 and -4 were down-regulated. The rest of the $C l A B C B$ family genes were significantly upregulated.

\section{Discussion}

Auxin, as a key regulator of plant growth and development through polar auxin transport, is involved in response to environmental stress $[2,3]$. In recent years, the molecular mechanism of auxin transport has been gradually elucidated in Arabidopsis. On the basis of the function in auxin transport, auxin transport proteins are divided into three major families. They were AUX LAX influx carriers, PIN efflux carriers and $\mathrm{ABCB}$ efflux /conditional transporters. With the publication of the C.lanatus genome [58], we have a further understanding of the molecular mechanism of auxin transport in watermelon. In the current research, we identified 33 auxin transporter genes in watermelon and concentrated on the expression profiles of ClLAX, $C I P I N$ and $C l A B C B$ genes to elucidate how the auxin transporters were involved in watermelon responses to salt, drought or cold stresses and the phase of grafting.

\section{Characterisation of CILAX, CIPIN and CIABCB genes in watermelon}

Watermelon (Clanatus), an important vegetable crop with $425 \mathrm{Mb}$ genome size, accounts for approximately
$7 \%$ of the agricultural area worldwide based on the statistics from Food and Agriculture Organization. Our study characterized the complete ClLAX, ClPIN and ClABCB family genes in watermelon. The numbers of CILAX and CIPIN family genes in watermelon were more than those in Arabidopsis. The number of $L A X$ genes in watermelon is around twice the number in Arabidopsis. The number of $C l A B C B$ family genes in watermelon is less than that in Arabidopsis. Arabidopsis homologous genes are widely existed in watermelon genome. The relatively similar protein sequence identities of the LAX, PIN and ABCB proteins between watermelon and Arabidopsis implied that all these genes originated from one or more common genes [59]. Two sister pair genes were identified as orthologue genes between watermelon and Arabidopsis in PIN family with bootstrap values $\geq 99 \%$. Two sister pair genes were identified in $A B C B$ family between watermelon and Arabidopsis. However, no orthologue gene pairs were identified in $L A X$ family between watermelon and Arabidopsis (bootstrap value $\geq 99 \%$ ). CILAX, CIPIN and ClABCB proteins contain multiple transmembrane helices, which are similar to the conserved structure of auxin transport protein from Arabidopsis [37, 57]. The ClLAX proteins only contain one group of transmembrane helices, and there is no variable middle hydrophilic region in ClLAX proteins (Additional file 4: Figure S1). Two groups of transmembrane helices existed in the $\mathrm{N}$ - and $\mathrm{C}$-termini and a highly heterogeneous hydrophilic region was located 


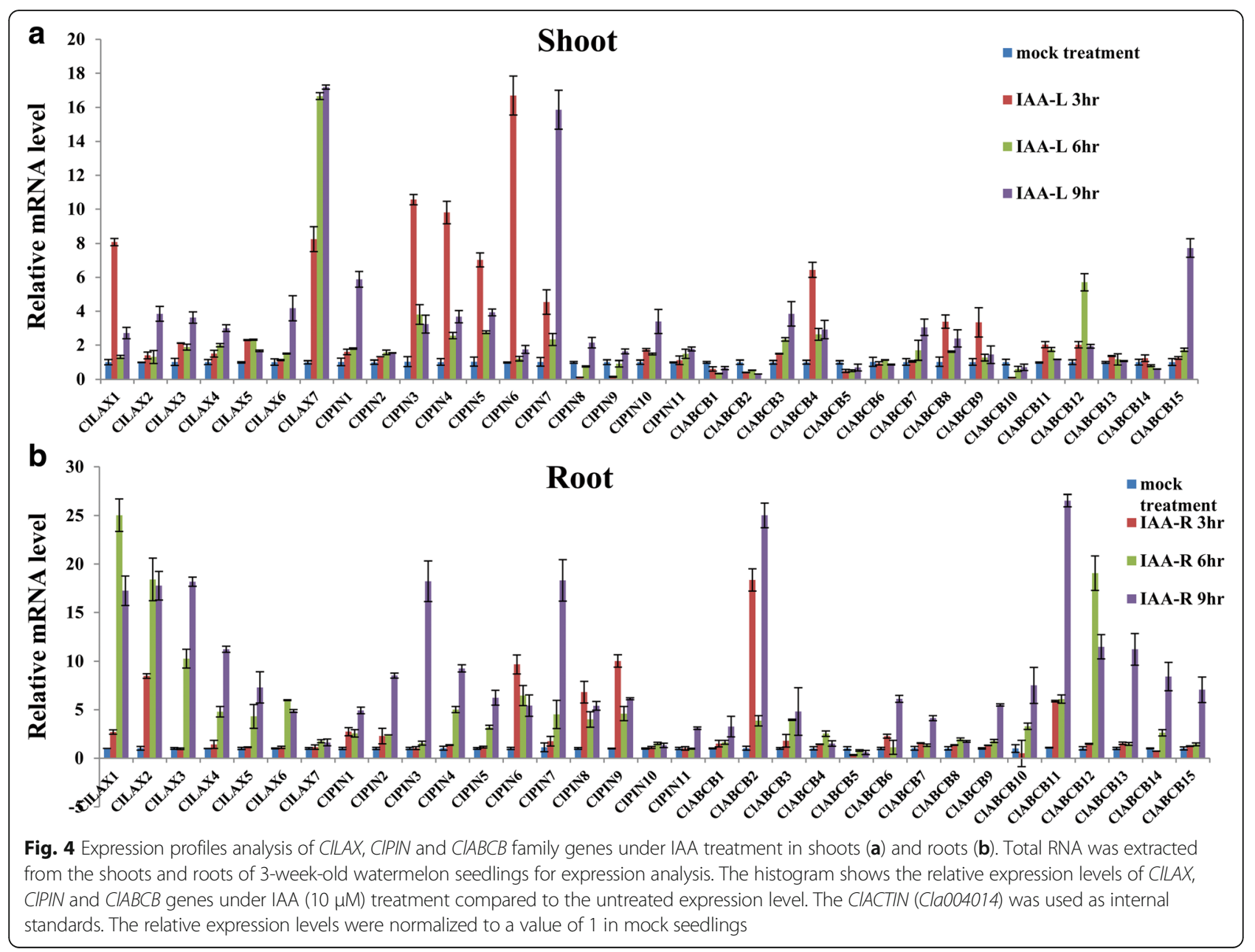

at the centre in most $\mathrm{ClPIN}$ and $\mathrm{ClABCB}$ proteins (Additional file 4: Figure S1). The PIN protein hydrophilic loop is partially modular for the trafficking behaviour and the intracellular trafficking is plastic depending on cell type and developmental stage [60]. The presence of the hydrophilic region in PIN and ABCB proteins from watermelon suggested that they had a similar trafficking behaviour to Arabidopsis. Phylogenetic and domain structural analyses showed that PIN and ABCB protein functions were conserved between watermelon and Arabidopsis [61].

\section{Tissue-specific expression analysis of CILAX, CIPIN and $C I A B C B$ genes}

Tissue-specific expression analysis of ClLAX, ClPIN and $C l A B C B$ genes indicated that the transcriptional level of these auxin transporter genes expressed in the roots, cotyledons, leaves, shoots and flowers varied greatly. $L A X, P I N$ and $A B C B$ genes have been found to be involved in plant growth and development previously $[16,43,57]$. The differential expression level of most of ClLAX, ClPIN and ClABCB genes in different tissues showed that they might be involved in the regulation of growth and development in watermelon. In spite of the conservation in protein structure, the ClLAX expressed among tissues/organs with different intensities. The high identity of $L A X$ genes between watermelon and Arabidopsis at the protein level indicated that ClLAX genes might have conserved function as their Arabidopsis orthologue genes (Additional file 2: Table S2). In Arabidopsis, four $A U X / L A X$ genes have complementary and non-redundant expression profiles in the roots and facilitate distinct developmental process: AtAUX1 functions in root gravitropism [12] and root hair development [62]; AtLAX2 functions in vascular development and cell division in the QC [16, 17]; AtLAX3 and AtAUX1 coordinately regulates apical hook development [63] and lateral root development [13]. The ClLAX genes might play similar or different roles during watermelon development because of their variety of expression patterns. PIN family genes have been previously elucidated to participate in growth and development in a variety of plant species [27]. AtPIN1 is expressed during early embryonic development. Later, it expressed in the primary root and in the inflorescence stems [33]. Three 


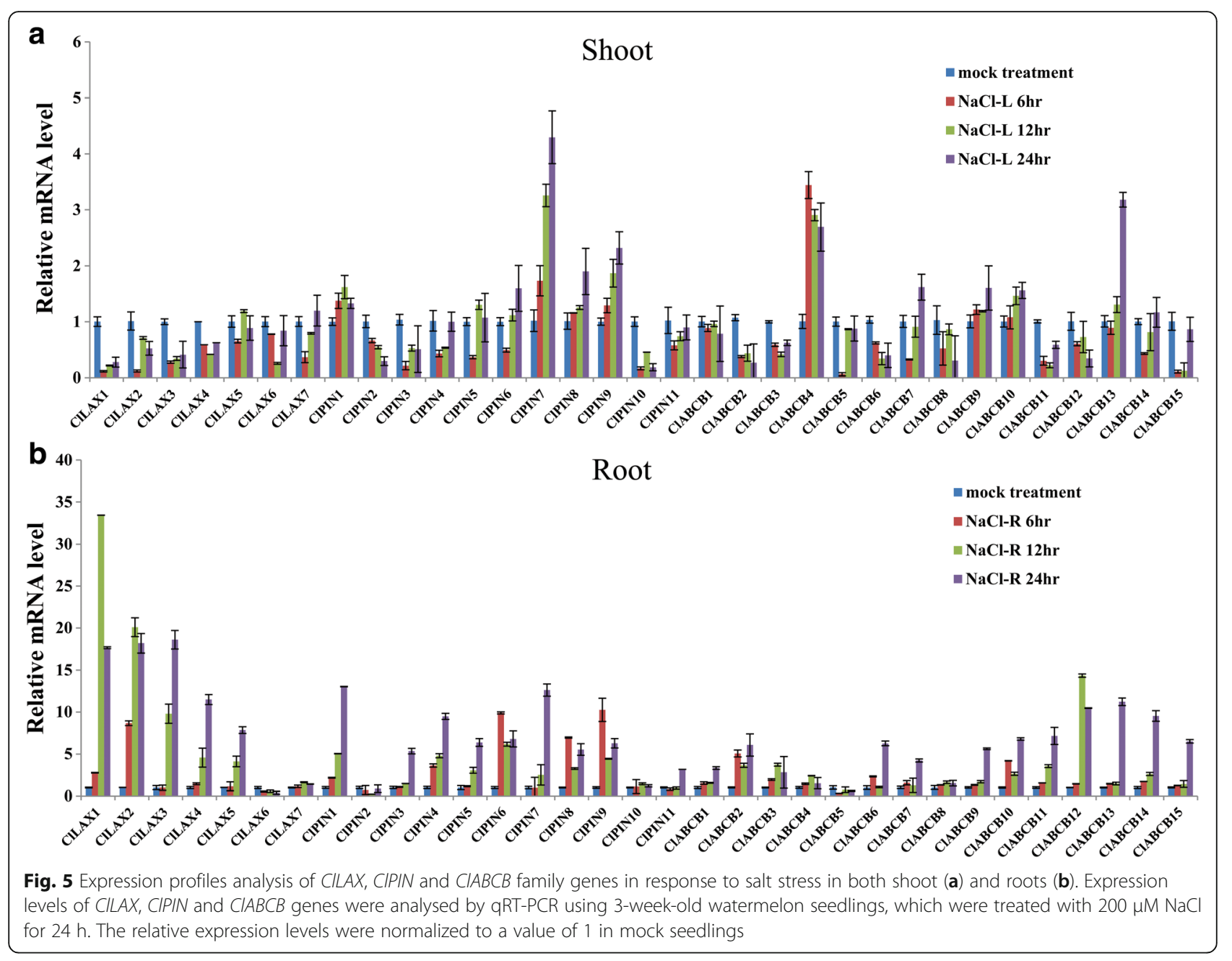

OsPIN5 homologous genes exist in rice genome. OsPIN5 $a$ and OsPIN5c weakly expressed in roots, highly expressed in leaves, shoot apex, and panicle. OsPIN5b expressed in young panicles and may be involved in inflorescence formation in rice [37]. ZmPIN1b, an orthologue of AtPIN1, is highly expressed during female inflorescence development in maize [34]. Our data showed that two ClPIN genes (ClPIN3 and ClPIN10) were more highly expressed in the roots than in any other tissues, suggesting that they may function in root development. The subclass $B$ of the ABC superfamily includes the majority of proteins that are able to bind and transport auxin in Arabidopsis. However, other members transport other substrates. The AtABCB14 was first described as a malate transporter [49]. To date, there has been no functional characterization of the $\mathrm{ABCBs}$ in watermelon and the likely role of members in auxin transport. We sought to identify candidate $C l A B C B$ s with the function of auxin transport. Our phylogenetic analysis showed that the ClABCB11 and ClABCB14 cluster along with AtABCB19 and AtABCB1, respectively, both of which were known as
IAA transporters. Further investigation, including celltype specific expression pattern analysis of these family genes and expression patterns during different developmental processes, is required to reveal how these genes participated in the development regulation functions.

\section{Expression patterns analysis of CILAX, CIPIN and CIABCB genes upon IAA treatment}

To determine whether the auxin transporters were involved in auxin signal, we analysed the gene expression profiles of these genes at different times under IAA treatment. In Arabidopsis, AtLAX1 and AtLAX3 were highly induced by 2, 4-D in the roots [16]. The expression of AtPIN6 is upregulated by auxin though repressive chromatin modification [64]. The expression level of $A t A B C B 4$ is enhanced by 2, 4-D treatment [65] and $A t A B C B 1$ is also up-regulated by exogenous auxin application [41]. OsABCB14 was induced rapidly by exogenous auxin in rice. The expression of OsPIN1a showed a fivefold increase after IAA treatment [37]. In maize, most of the auxin transporter genes responded to auxin treatment 


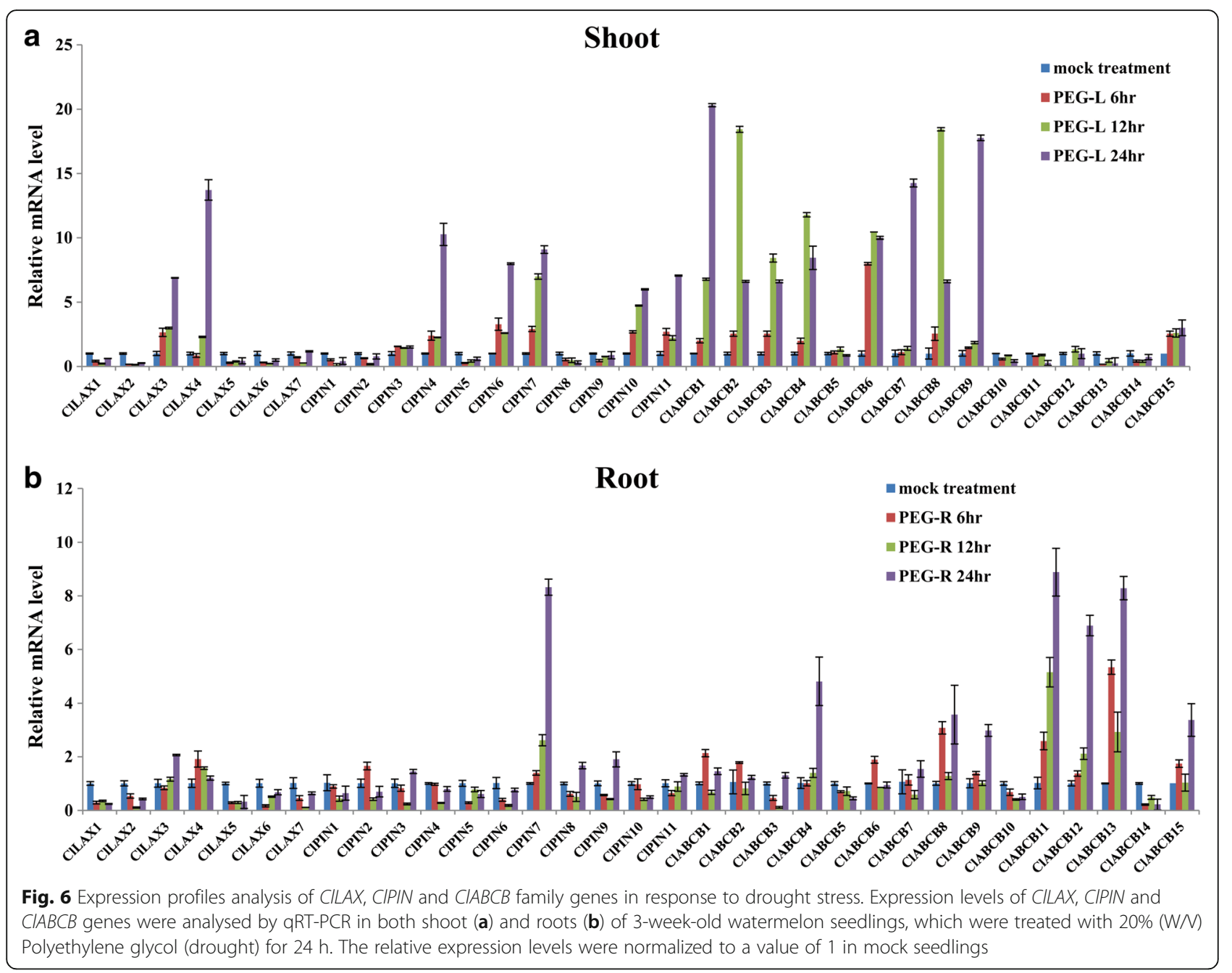

in both shoots and roots [24]. ClPIN5 and ClPIN7, two orthologue genes of AtPIN1 in watermelon, were also drastically induced by IAA treatment. $C l A B C B 14$ and ClABCB11, the orthologue of AtABCB1and AtABCB19 in watermelon, respectively, were up-regulated after IAA treatment in the roots.

\section{CILAX, CIPIN and CIABCB genes were related to salt, drought, cold and grafting response}

As one of the most important phytohormones, auxin regulates plant growth and mediates various environmental stress responses by controlling several auxin-responsive genes. Recently, evidence has indicated that environmental stresses change auxin distribution and homeostasis mediated by auxin transporters $[66,67]$. It has been reported that various abiotic signals can change auxin distribution by modulating the expression of auxin transporter genes [66]. In soybean, abiotic stress and hormonal treatments altered auxin accumulation and distribution in the roots. In addition, under these conditions, some GmPIN genes might contribute to auxin distribution and homeostasis
[68]. In rice, overexpression of OsPIN3t improved drought tolerance and knockdown of OsPIN3t led to insensitive to drought stress [36]. Therefore, auxin transporters might mediate the crosstalk between auxin and abiotic stresses. The majority of the ClLAX, ClPIN and ClABCB genes were responsive to cold, drought and high salinity both in the shoot and root tissues. The expression profiling of ClLAX, ClPIN and ClABCB genes changed under abiotic stresses, which might accelerate or decelerate the transportation of endogenous auxin in watermelon seedlings. The responses of auxin transport genes to highly saline and drought stress and their different expression profiles indicated that the transcriptional expressions of these auxin transporter genes were regulated by the different physiological signals. Auxin redistribution and transport may be required for watermelon when it responded to abiotic stresses.

Low-temperature stress is a common adversity, which is often encountered in plant cultivation [69]. Many studies have indicated that a relationship between auxin and low temperature stress [70]. Cold stress changes the 


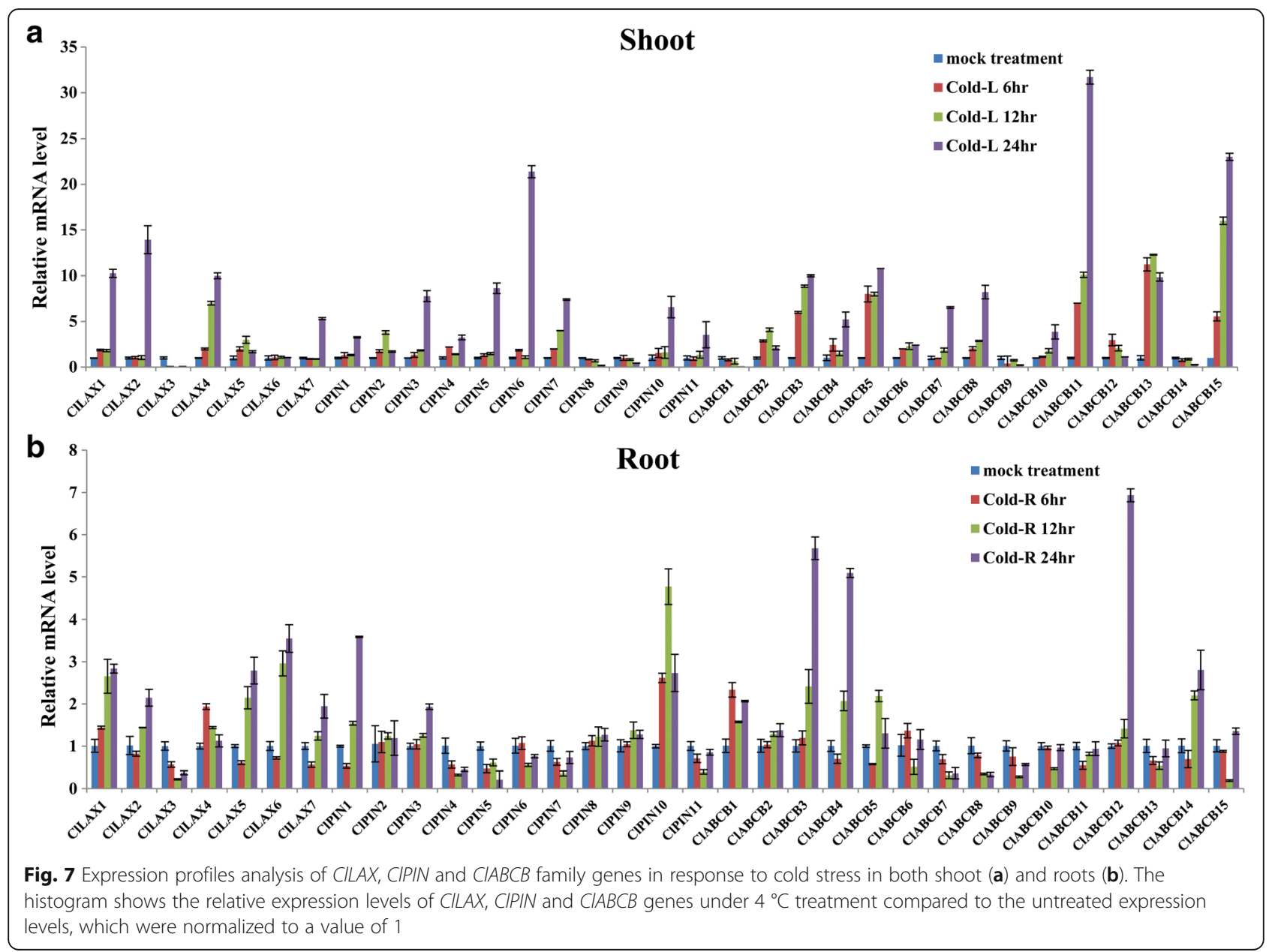

growth and development of plants closely related to the intracellular concentration gradient of auxin, which is regulated by asymmetric localisation and intracellular trafficking of auxin carriers. For example, the asymmetric redistribution and intracellular cycling of AtPIN3 protein were blocked by cold stress. Cold stress also inhibits the intracellular cycling of AtPIN2 [71]. During low temperature stress, the immobilisation of PINs represents a selective process to regulate the activity of specific proteins, which provides a mechanistic basis to explain the role of auxin in regulating the growth and development of plant under cold stress. Watermelon is

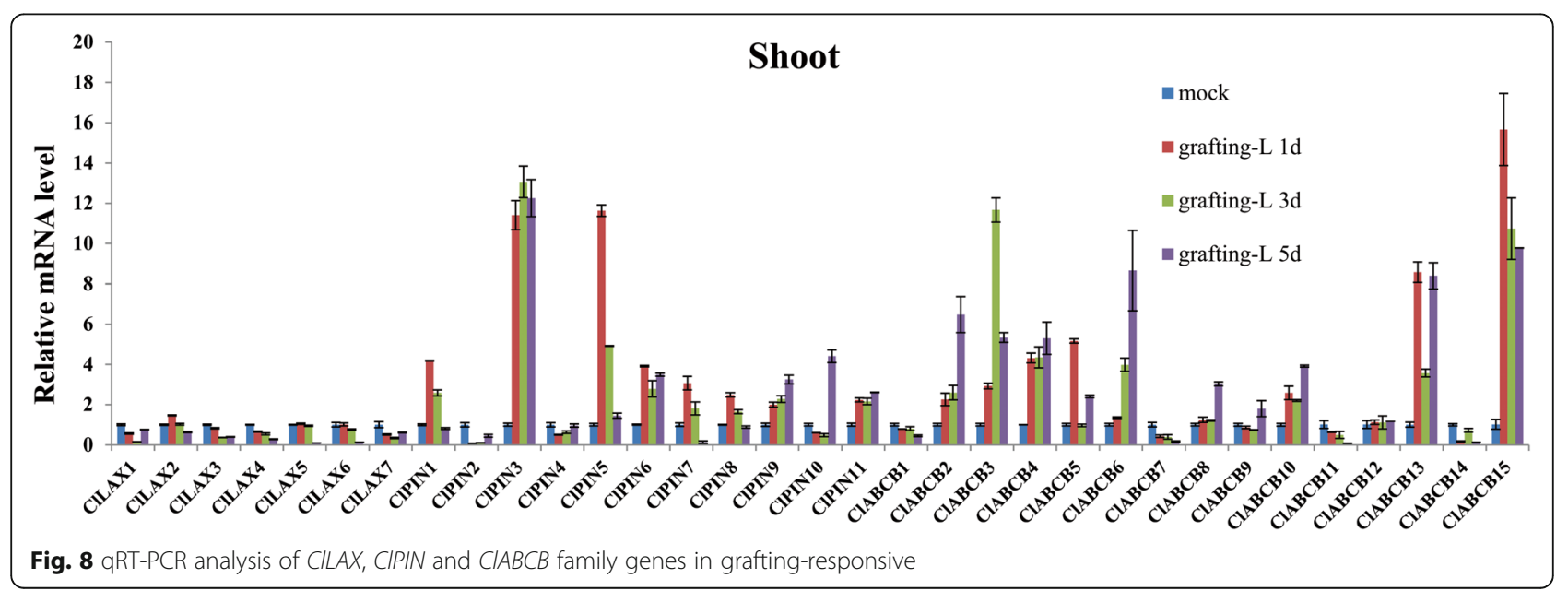


an annual herb of the gourd family, originating from tropical Africa. Most varieties of watermelon are weak to cold hardiness and vulnerable to seasonal restrictions. The transcriptional level of most ClLAX, ClPIN and $C l A B C B$ genes also changed during the cold treatment, which suggested that these genes may function in the mechanism that helps watermelon tolerate cold stress.

Auxin plays a pivotal role in development, and the mode of auxin flow through a tissue determines the sites of vein formation [72]. Similarly, auxin promotes the formation of the xylem and phloem in callus [73]. In Arabidopsis, normal vein development depends on polar auxin transport and can be modified by auxin transport inhibitors or mutations of auxin transport genes [74]. The expression levels of most ClLAX, ClPIN and $C l A B C B$ genes also changed during grafting. This condition suggested that these genes might play a significant role in auxin transported to graft junction, thereby promoting wound healing and vascular formation.

Some members of auxin transporter family genes have been found to engage in the response to abiotic stresses (such as alkaline, drought, heavy metal, high salinity, nutritional deficiency and cold stress). In Arabidopsis, AtAUX1 played an important role in plant tolerance to oxidative stress caused by arsenite [75]. Shoot-supplied ammonium influenced root architecture by interfering with AUX1-dependent auxin transport [76]. Auxin homeostasis is changed in roots under cadmium stress via AUX1 proteins both in Arabidopsis and rice [22, 77]. Aluminium toxicity altered auxin distribution through AtPIN2 and AtAUX1 auxin transporter proteins [78]. AtPIN2 helps roots adapt to alkaline stress by modulating root tip proton secretion [79]. The expression levels of AtPIN3 and AtPIN1 genes were reduced under oxidative stress caused by alloxan [80]. AtABCB genes responding to light, $\mathrm{CO}_{2}$, phytochromes and cryptochromes have rarely been reported $[49,81]$. The expression of SbLAX4 gene was dramatically reduced under salt and drought stresses [23]. These physiological and genetic evidence suggests that auxin transporters respond to abiotic stress. The expression profiling of ClLAX, ClPIN and ClABCB gene changes under abiotic stress may affect endogenous auxin redistribution and concentration. Auxin homeostasis is a crucial process for plant to adapt to changing environments. Further studies, including molecular biology and reverse genetics analysis of each watermelon auxin transporter, will extend our understanding of the regulation mechanisms between auxin transporters and abiotic stresses.

\section{Conclusions}

In summary, we characterized the transcript pattern of ClLAX, ClPIN and ClABCB family genes in watermelon under exogenous IAA treatments or adversity stress.
The distinct expressions of ClLAX, ClPIN and ClABCB genes indicated different regulatory action of these genes in watermelon tolerance to abiotic stresses.

\section{Additional files}

Additional file 1: Table S1. List of qRT-PCR primers used in the present study. (DOCX $1082 \mathrm{~kb}$ )

Additional file 2: Table S2. Percent Identity Matrix of LAX family bweteen waternelon and Arabidopsis. (DOCX $648 \mathrm{~kb}$ )

Additional file 3: Table S3. qRT-PCR values of the CILAX, CIPIN and $C I A B C B$ family genes in five tissues. (DOCX $1910 \mathrm{~kb}$ )

Additional file 4: Figure S1. Transmembrane helices of CILAX, CIPIN and $C I A B C B$. Protein transmembrane topology was analyzed using the TMHHM Server. (DOCX 1872 kb)

\section{Funding}

This work was supported by the National Natural Science Foundation of China (grant no. 51375460), Young talent training project of Zhejiang Academy of Agricultural Sciences(2016R23R08E05), Natural Science Foundation of Zhejiang Province (grant no. LQ17C150003). Scientific and Technological Program of Hangzhou (2015R23A70D05).

Availability of data and materials

All related data are available within the manuscript and its additional files.

Authors' contributions

CLY prepared the manuscript draft and contributed the experiment. WQD provided the materials. YHZ analysed the genome sequencing data. ZAH revised the manuscript. $Z M L$ contributed to the design and performed the statistical analysis. SK and CHZ assisted to draft the manuscript. All authors are read and approved the final manuscript.

\section{Competing interests}

The authors declare that they have no competing interests.

Consent for publication

Not applicable.

Ethics approval and consent to participate

Not applicable

\section{Publisher's Note}

Springer Nature remains neutral with regard to jurisdictional claims in published maps and institutional affiliations.

\section{Author details}

${ }^{1}$ Vegetable Research Institute, Zhejiang Academy of Agricultural Sciences, Hangzhou 310021, China. ${ }^{2}$ State Key Laboratory of Plant Physiology and Biochemistry, College of Life Sciences, Zhejiang University, Hangzhou 310058, China. ${ }^{3}$ Institute of Vegetable Sciences, Wenzhou Academy of Agricultural Sciences, Wenzhou Vocational College of Science and Technology, Key Lab of Crop breeding in South Zhejiang, Wenzhou 325014, China. ${ }^{4}$ Dempartment of Horticulture, Kangwon National University, Chuncheon 200-2071, Korea.

Received: 30 October 2016 Accepted: 30 March 2017

Published online: 07 April 2017

\section{References}

1. Park JE, Park JY, Kim YS, Staswick PE, Jeon J, Yun J, Kim SY, Kim J, Lee YH, Park CM. GH3-mediated auxin homeostasis links growth regulation with stress adaptation response in Arabidopsis. J Biol Chem. 2007;282:10036-46.

2. Zahir ZA, Shah MK, Naveed M, Akhter MJ. Substrate-dependent auxin production by Rhizobium phaseoli improves the growth and yield of Vigna radiata L. under salt stress conditions. J Microbiol Biotechn. 2010;20:1288-94.

3. Du H, Liu H, Xiong L. Endogenous auxin and jasmonic acid levels are differentially modulated by abiotic stresses in rice. Front Plant Sci. 2013;4:397. 
4. Tanaka H, Dhonukshe P, Brewer PB, Friml J. Spatiotemporal asymmetric auxin distribution: a means to coordinate plant development. Cell Mol Life Sci. 2006:63:2738-54.

5. Potters G, Pasternak TP, Guisez Y, Palme KJ, Jansen MA. Stress-induced morphogenic responses: growing out of trouble? Trends Plant Sci. 2007;12:98-105.

6. Tognetti VB, Van Aken O, Morreel K, Vandenbroucke K, van de Cotte B, De Clercq I, Chiwocha S, Fenske R, Prinsen E, Boerjan W, Genty B, Stubbs KA, Inze D, Van Breusegem F. Perturbation of indole-3-butyric acid homeostasis by the UDP-glucosyltransferase UGT74E2 modulates Arabidopsis architecture and water stress tolerance. Plant Cell. 2010;22:2660-79.

7. Swarup R, Bennett M. Auxin transport: the fountain of life in plants? Dev Cell. 2003:5:824-6.

8. Swarup R, Kargul J, Marchant A, Zadik D, Rahman A, Mills R, Yemm A, May S, Williams L, Millner P, Tsurumi S, Moore I, Napier R, Kerr ID, Bennett MJ. Structure-function analysis of the presumptive Arabidopsis auxin permease AUX1. Plant Cell. 2004:16:3069-83.

9. Petrasek J, Mravec J, Bouchard R, Blakeslee JJ, Abas M, Seifertova D, Wisniewska J, Tadele Z, Kubes M, Covanova M, Dhonukshe P, Skupa P Benkova E, Perry L, Krecek P, Lee OR, Fink GR, Geisler M, Murphy AS, Luschnig C, Zazimalova E, Friml J. PIN proteins perform a rate-limiting function in cellular auxin efflux. Science. 2006;312:914-8.

10. Cho M, Lee SH, Cho HT. P-glycoprotein4 displays auxin efflux transporterlike action in Arabidopsis root hair cells and tobacco cells. Plant Cell. 2007;19:3930-43.

11. Bennett MJ, Marchant A, Green HG, May ST, Ward SP, Millner PA, Walker AR, Schulz B, Feldmann KA. Arabidopsis AUX1 gene: a permease-like regulator of root gravitropism. Science. 1996;273:948-50.

12. Swarup R, Friml J, Marchant A, Ljung K, Sandberg G, Palme K, Bennett M. Localization of the auxin permease AUX1 suggests two functionally distinct hormone transport pathways operate in the Arabidopsis root apex. Genes Dev. 2001;15:2648-53.

13. Swarup K, Benkova E, Swarup R, Casimiro I, Peret B, Yang Y, Parry G, Nielsen E, De Smet I, Vanneste S, Levesque MP, Carrier D, James N, Calvo V, Ljung K, Kramer E, Roberts R, Graham N, Marillonnet S, Patel K, Jones JD, Taylor CG, Schachtman DP, May S, Sandberg G, Benfey P, Friml J, Kerr I, Beeckman T, Laplaze L, Bennett MJ. The auxin influx carrier LAX3 promotes lateral root emergence. Nat Cell Biol. 2008;10:946-54.

14. Marchant A, Bhalerao R, Casimiro I, Eklof J, Casero PJ, Bennett M, Sandberg G. AUX1 promotes lateral root formation by facilitating indole-3-acetic acid distribution between sink and source tissues in the Arabidopsis seedling. Plant Cell. 2002;14:589-97.

15. Yang Y, Hammes UZ, Taylor CG, Schachtman DP, Nielsen E. High-affinity auxin transport by the AUX1 influx carrier protein. Curr Biol. 2006;16:1123-7.

16. Peret B, Swarup K, Ferguson A, Seth M, Yang $Y$, Dhondt $S$, James $N$, Casimiro I, Perry P, Syed A, Yang H, Reemmer J, Venison E, Howells C, PerezAmador MA, Yun J, Alonso J, Beemster GT, Laplaze L, Murphy A, Bennet MJ, Nielsen E, Swarup R. AUXLAX genes encode a family of auxin influx transporters that perform distinct functions during Arabidopsis development. Plant Cell. 2012;24:2874-85.

17. Zhang W, Swarup R, Bennett M, Schaller GE, Kieber JJ. Cytokinin induces cell division in the quiescent center of the Arabidopsis root apical meristem. Curr Biol. 2013;23:1979-89.

18. Bainbridge K, Guyomarc'h S, Bayer E, Swarup R, Bennett M, Mandel T, Kuhlemeier C. Auxin influx carriers stabilize phyllotactic patterning. Genes Dev. 2008:22:810-23.

19. Ugartechea-Chirino $Y$, Swarup R, Swarup K, Peret B, Whitworth M, Bennett M, Bougourd S. The AUX1 LAX family of auxin influx carriers is required for the establishment of embryonic root cell organization in Arabidopsis thaliana. Ann Bot. 2010;105:277-89.

20. Hoyerova K, Perry L, Hand P, Lankova M, Kocabek T, May S, Kottova J, Paces J, Napier R, Zazimalova E. Functional characterization of PaLAX1, a putative auxin permease, in heterologous plant systems. Plant Physiol. 2008;146:1128-41.

21. Zhao H, Ma T, Wang $X$, Deng $Y$, Ma H, Zhang R, Zhao J. OsAUXX1 controls lateral root initiation in rice (Oryza sativa L.). Plant Cell Environ. 2014;38:2208-22.

22. Yu C, Sun C, Shen C, Wang S, Liu F, Liu Y, Chen Y, Li C, Qian Q, Aryal B, Geisler M, Jiang DA, Qi Y. The auxin transporter, OsAUX1, is involved in primary root and root hair elongation and in $\mathrm{Cd}$ stress responses in rice (Oryza sativa L.). Plant J. 2015;83:818-30.
23. Shen C, Bai Y, Wang S, Zhang S, Wu Y, Chen M, Jiang D, Qi Y. Expression profile of PIN, AUX/LAX and PGP auxin transporter gene families in Sorghum bicolor under phytohormone and abiotic stress. FEBS J. 2010;277:2954-69.

24. Yue R, Tie S, Sun T, Zhang L, Yang Y, Qi J, Yan S, Han X, Wang H, Shen C. Genome-wide identification and expression profiling analysis of ZMPIN, $Z m P I L S, Z m L A X$ and $Z m A B C B$ auxin transporter gene families in maize (Zea mays L.) under various abiotic stresses. Plos One. 2015;10:e0118751.

25. Chai C, Wang Y, Valliyodan B, Nguyen HT. Comprehensive analysis of the soybean (Glycine max) GmLAX auxin transporter gene family. Front Plant Sci. 2016;7:282.

26. Grunewald W, Friml J. The march of the PINs: developmental plasticity by dynamic polar targeting in plant cells. EMBO J. 2010;29:2700-14.

27. Robert HS, Grones P, Stepanova AN, Robles LM, Lokerse AS, Alonso JM, Weijers D, Friml J. Local auxin sources orient the apical-basal axis in Arabidopsis embryos. Curr Biol. 2013;23:2506-12.

28. Ganguly A, Lee SH, Cho M, Lee OR, Yoo H, Cho HT. Differential auxintransporting activities of PIN-FORMED proteins in Arabidopsis root hair cells. Plant Physiol. 2010;153:1046-61.

29. Friml J, Benkova E, Blilou I, Wisniewska J, Hamann T, Ljung K, Woody S, Sandberg G, Scheres B, Jurgens G, Palme K. AtPIN4 mediates sink-driven auxin gradients and root patterning in Arabidopsis. Cell. 2002;108:661-73.

30. Mravec J, Skupa P, Bailly A, Hoyerova K, Krecek P, Bielach A, Petrasek J, Zhang J, Gaykova V, Stierhof YD, Dobrev PI, Schwarzerova K, Rolcik J, Seifertova D, Luschnig C, Benkova E, Zazimalova E, Geisler M, Friml J. Subcellular homeostasis of phytohormone auxin is mediated by the ERlocalized PIN5 transporter. Nature. 2009:459:1136-U1127.

31. Dal Bosco C, Dovzhenko A, Liu X, Woerner N, Rensch T, Eismann M, Eimer S, Hegermann J, Paponov IA, Ruperti B, Heberle-Bors E, Touraev A, Cohen JD, Palme K. The endoplasmic reticulum localized PIN8 is a pollen-specific auxin carrier involved in intracellular auxin homeostasis. Plant J. 2012;71:860-70

32. Wisniewska J, Xu J, Seifertova D, Brewer PB, Ruzicka K, Blilou I, Rouquie D, Benkova E, Scheres B, Friml J. Polar PIN localization directs auxin flow in plants. Science. 2006;312:883.

33. Galweiler L, Guan C, Muller A, Wisman E, Mendgen K, Yephremov A, Palme K. Regulation of polar auxin transport by AtPIN1 in Arabidopsis vascular tissue. Science. 1998;282:2226-30.

34. Carraro N, Forestan C, Canova S, Traas J, Varotto S. ZmPIN1a and ZmPIN1b encode two novel putative candidates for polar auxin transport and plant architecture determination of maize. Plant Physiol. 2006;142:254-64.

35. Forestan C, Meda S, Varotto S. ZmPIN1-mediated auxin transport is related to cellular differentiation during maize embryogenesis and endosperm development. Plant Physiol. 2010;152:1373-90.

36. Xu M, Zhu L, Shou H, Wu P. A PIN1 family gene, OsPIN1, involved in auxindependent adventitious root emergence and tillering in rice. Plant Cell Physiol. 2005;46:1674-81

37. Wang JR, Hu H, Wang GH, Li J, Chen JY, Wu P. Expression of PIN genes in rice (Oryza sativa L.): tissue specificity and regulation by hormones. Mol Plant. 2009;2:823-31.

38. Chen $Y$, Fan X, Song W, Zhang Y, Xu G. Over-expression of OsPIN2 leads to increased tiller numbers, angle and shorter plant height through suppression of OsLAZY1. Plant Biotechnol J. 2012;10:139-49.

39. Zhang Q, Li J, Zhang W, Yan S, Wang R, Zhao J, Li Y, Qi Z, Sun Z, Zhu Z. The putative auxin efflux carrier OsPIN3t is involved in the drought stress response and drought tolerance. Plant J. 2012;72:805-16.

40. Kang J, Park J, Choi H, Burla B, Kretzschmar T, Lee Y, Martinoia E. Plant ABC transporters. Arabidopsis Book. 2011;9:e0153.

41. Geisler M, Murphy AS. The ABC of auxin transport: the role of $p$ glycoproteins in plant development. FEBS Lett. 2006:580:1094-102.

42. Cho M, Cho HT. The function of $A B C B$ transporters in auxin transport. Plant Signal Behav. 2013;8:e22990.

43. Kaneda M, Schuetz M, Lin BS, Chanis C, Hamberger B, Western TL, Ehlting J, Samuels AL. ABC transporters coordinately expressed during lignification of Arabidopsis stems include a set of ABCBs associated with auxin transport. J Exp Bot. 2011;62:2063-77.

44. Kamimoto Y, Terasaka K, Hamamoto M, Takanashi K, Fukuda S, Shitan N, Sugiyama A, Suzuki H, Shibata D, Wang B, Pollmann S, Geisler M, Yazaki K. Arabidopsis ABCB21 is a facultative auxin importer/exporter regulated by cytoplasmic auxin concentration. Plant Cell Physiol. 2012;53:2090-100.

45. Lin $\mathrm{R}$, Wang $\mathrm{H}$. Two homologous ATP-binding cassette transporter proteins, AtMDR1 and AtPGP1, regulate Arabidopsis photomorphogenesis and root 
development by mediating polar auxin transport. Plant Physiol. 2005;138: 949-64.

46. Bandyopadhyay A, Blakeslee JJ, Lee OR, Mravec J, Sauer M, Titapiwatanakun B, Makam SN, Bouchard R, Geisler M, Martinoia E, Friml J, Peer WA, Murphy AS. Interactions of PIN and PGP auxin transport mechanisms. Biochem Soc Trans. 2007:35:137-41.

47. Christie JM, Yang H, Richter GL, Sullivan S, Thomson CE, Lin J, Titapiwatanakun B, Ennis M, Kaiserli E, Lee OR, Adamec J, Peer WA, Murphy AS. phot1 inhibition of ABCB19 primes lateral auxin fluxes in the shoot apex required for phototropism. PLoS Biol. 2011;9:e1001076.

48. Yang H, Murphy AS. Functional expression and characterization of Arabidopsis ABCB, AUX 1 and PIN auxin transporters in Schizosaccharomyces pombe. Plant J. 2009;59:179-91.

49. Lee M, Choi Y, Burla B, Kim YY, Jeon B, Maeshima M, Yoo JY, Martinoia E, Lee $Y$. The $A B C$ transporter AtABCB14 is a malate importer and modulates stomatal response to $\mathrm{CO}_{2}$. Nat Cell Biol. 2008;10:1217-23.

50. Xu Y, Zhang S, Guo H, Wang S, Xu L, Li C, Qian Q, Chen F, Geisler M, Qi Y, de Jiang A. OSABCB14 functions in auxin transport and iron homeostasis in rice (Oryza sativa L.). Plant J. 2014;79:106-17.

51. Carraro N, Tisdale-Orr TE, Clouse RM, Knoller AS, Spicer R. Diversification and expression of the PIN, AUX/LAX, and ABCB families of putative auxin transporters in Populus. Front Plant Sci. 2012;3:17.

52. Noh J, Kim JM, Sheikh S, Lee SG, Lim JH, Seong MH, Jung GT. Effect of heat treatment around the fruit set region on growth and yield of watermelon [Citrullus lanatus (Thunb.) Matsum. and Nakai]. Physiol Mol Biol Pla. 2013;19:509-14.

53. Lee J-M, Kubota C, Tsao SJ, Bie Z, Echevarria PH, Morra L, Oda M. Current status of vegetable grafting: Diffusion, grafting techniques, automation. Sci Hortic-Amsterdam. 2010;127:93-105.

54. Carrier DJ, Bakar NT, Swarup R, Callaghan R, Napier RM, Bennett MJ, Kerr ID. The binding of auxin to the Arabidopsis auxin influx transporter AUX1. Plant Physiol. 2008;148:529-35.

55. Holub EB. The arms race is ancient history in Arabidopsis, the wildflower Nat Rev Genet. 2001;2:516-27.

56. Bowers JE, Chapman BA, Rong J, Paterson AH. Unravelling angiosperm genome evolution by phylogenetic analysis of chromosomal duplication events. Nature. 2003;422:433-8.

57. Paponov IA, Teale WD, Trebar M, Blilou I, Palme K. The PIN auxin efflux facilitators: evolutionary and functional perspectives. Trends Plant Sci. 2005;10:170-7

58. Guo S, Zhang J, Sun H, Salse J, Lucas WJ, Zhang H, Zheng Y, Mao L, Ren Y, Wang Z, Min J, Guo X, Murat F, Ham BK, Zhang Z, Gao S, Huang M, Xu Y, Zhong S, Bombarely A, Mueller LA, Zhao H, He H, Zhang Y, Zhang Z, Huang S, Tan T, Pang E, Lin K, Hu Q, Kuang H, Ni P, Wang B, Liu J, Kou Q, Hou W, Zou X, Jiang J, Gong G, Klee K, Schoof H, Huang Y, Hu X, Dong S, Liang D, Wang J, Wu K, Xia Y, Zhao X, Zheng Z, Xing M, Liang X, Huang B, Lv T, Wang J, Yin Y, Yi H, Li R, Wu M, Levi A, Zhang X, Giovannoni JJ, Wang J, Li $Y$, Fei Z, Xu Y. The draft genome of watermelon (Citrullus lanatus) and resequencing of 20 diverse accessions. Nat Genet. 2013;45:51-8.

59. Forestan C, Farinati S, Varotto $S$. The maize PIN gene family of auxin transporters. Front Plant Sci. 2012;3:16.

60. Ganguly A, Park M, Kesawat MS, Cho HT. Functional analysis of the hydrophilic loop in intracellular trafficking of Arabidopsis PIN-FORMED proteins. Plant Cell. 2014;26:1570-85.

61. Knoller AS, Blakeslee JJ, Richards EL, Peer WA, Murphy AS. Brachytic2/ ZmABCB1 functions in IAA export from intercalary meristems. J Exp Bot. 2010;61:3689-96.

62. Jones AR, Kramer EM, Knox K, Swarup R, Bennett MJ, Lazarus CM, Leyser HMO, Grierson CS. Auxin transport through non-hair cells sustains root-hair development. Nat Cell Biol. 2009;11:78-U156.

63. Vandenbussche F, Petrasek J, Zadnikova P, Hoyerova K, Pesek B, Raz V, Swarup R, Bennett M, Zazimalova E, Benkova E, Van Der Straeten D. The auxin influx carriers AUX1 and LAX3 are involved in auxin-ethylene interactions during apical hook development in Arabidopsis thaliana seedlings. Development. 2010;137:597-606.

64. Nisar N, Cuttriss AJ, Pogson BJ, Cazzonelli Cl. The promoter of the Arabidopsis PIN6 auxin transporter enabled strong expression in the vasculature of roots, leaves, floral stems and reproductive organs. Plant Signal Behav. 2014;9:e27898.
65. Terasaka K, Blakeslee JJ, Titapiwatanakun B, Peer WA, Bandyopadhyay A, Makam SN, Lee OR, Richards EL, Murphy AS, Sato F, Yazaki K. PGP4, an ATP binding cassette P-glycoprotein, catalyzes auxin transport in Arabidopsis thaliana roots. Plant Cell. 2005;17:2922-39.

66. Rahman A. Auxin: a regulator of cold stress response. Physiol Plant. 2013;147:28-35

67. Friml J. Subcellular trafficking of PIN auxin efflux carriers in auxin transport. Eur J Cell Biol. 2010;89:231-5.

68. Wang Y, Chai C, Valliyodan B, Maupin C, Annen B, Nguyen HT. Genomewide analysis and expression profiling of the PIN auxin transporter gene family in soybean (Glycine max). BMC Genomics. 2015;16:951.

69. Kreps JA, Wu Y, Chang HS, Zhu T, Wang X, Harper JF. Transcriptome changes for Arabidopsis in response to salt, osmotic, and cold stress. Plant Physiol. 2002;130:2129-41.

70. Gupta OP, Meena NL, Sharma I, Sharma P. Differential regulation of microRNAs in response to osmotic, salt and cold stresses in wheat. Mol Biol Rep. 2014:41:4623-9.

71. Shibasaki K, Uemura M, Tsurumi S, Rahman A. Auxin response in Arabidopsis under cold stress: underlying molecular mechanisms. Plant Cell. 2009:21:3823-38.

72. Sachs T. Polarity and the induction of organized vascular tissues. Ann Bot-London. 1969:33:263-75.

73. Wetmore RH, Rier JP. Experimental induction of vascular tissues in callus of angiosperms. Am J Bot. 1963;50:418-30

74. Sieburth LE. Auxin is required for leaf vein pattern in Arabidopsis. Plant Physiol. 1999:121:1179-90.

75. Krishnamurthy A, Rathinasabapathi B. Auxin and its transport play a role in plant tolerance to arsenite-induced oxidative stress in Arabidopsis thaliana. Plant Cell Environ. 2013;36:1838-49.

76. Li B, Li Q, Su Y, Chen H, Xiong L, Mi G, Kronzucker HJ, Shi W. Shoot-supplied ammonium targets the root auxin influx carrier AUX1 and inhibits lateral root emergence in Arabidopsis. Plant Cell Environ. 2011;34:933-46.

77. Hu YF, Zhou G, Na XF, Yang L, Nan WB, Liu X, Zhang YQ, Li JL, Bi YR. Cadmium interferes with maintenance of auxin homeostasis in Arabidopsis seedlings. J Plant Physiol. 2013:170:965-75.

78. Sun P, Tian QY, Chen J, Zhang WH. Aluminium-induced inhibition of root elongation in Arabidopsis is mediated by ethylene and auxin. J Exp Bot. 2010;61:347-56

79. Xu W, Jia L, Baluska F, Ding G, Shi W, Ye N, Zhang J. PIN2 is required for the adaptation of Arabidopsis roots to alkaline stress by modulating proton secretion. J Exp Bot. 2012;63:6105-14.

80. Pasternak T, Potters G, Caubergs R, Jansen MA. Complementary interactions between oxidative stress and auxins control plant growth responses at plant, organ, and cellular level. J Exp Bot. 2005;56:1991-2001.

81. Nagashima A, Suzuki G, Uehara Y, Saji K, Furukawa T, Koshiba T, Sekimoto M, Fujioka S, Kuroha T, Kojima M, Sakakibara H, Fujisawa N, Okada K, Sakai T. Phytochromes and cryptochromes regulate the differential growth of Arabidopsis hypocotyls in both a PGP19-dependent and a PGP19independent manner. Plant J. 2008;53:516-29.

\section{Submit your next manuscript to BioMed Central and we will help you at every step:}

- We accept pre-submission inquiries

- Our selector tool helps you to find the most relevant journal

- We provide round the clock customer support

- Convenient online submission

- Thorough peer review

- Inclusion in PubMed and all major indexing services

- Maximum visibility for your research

Submit your manuscript at www.biomedcentral.com/submit
Biomed Central 